\title{
Variable ventilation enhances ventilation without exacerbating injury in preterm lambs with respiratory distress syndrome
}

\author{
Clare A. Berry ${ }^{1}$, Béla Suki ${ }^{2}$, Graeme R. Polglase ${ }^{3}$ and J. Jane Pillow ${ }^{1}$
}

BACKGROUND: As compared with constant respiratory rate $(\mathrm{RR})$ and tidal volume $\left(V_{T}\right)$ during controlled conventional mechanical ventilation (CV), variable ventilation (VV) using the same breath-to-breath minute volume but variable $V_{\text {T }}$ and RRs enhances ventilation efficiency in preterm lambs. We hypothesized that if $V_{T}$ was adjusted to target permissive hypercarbia, $\mathrm{V}$ would result in more efficient gas exchange without increasing inflammatory and injurious responses in the lung.

METHODS: Preterm lambs at $129 \mathrm{~d}$ gestation were anesthetized, tracheotomized, and randomized to either CV $(n=8)$ or $\mathrm{V}(n=8)$ using the same initial average $V_{\mathrm{T}}$ and RR. Lung mechanics and gas exchange were measured intermittently, and average $V_{T}$ was adjusted to target partial pressure of arterial carbon dioxide $\left(\mathrm{PaCO}_{2}\right)$ of $40-50 \mathrm{~mm} \mathrm{Hg}$ for $3 \mathrm{~h}$. Lung injury and inflammation were assessed from bronchoalveolar lavage fluid, lung tissue, and peripheral blood.

RESULTS: W achieved permissive hypercarbia using a lower average $V_{T}$, peak inspiratory pressure, and elastance (increased compliance) as compared with CV. Oxygenation and markers of lung tissue inflammation or injury were not different apart from a lower wet:dry tissue ratio in the $\mathrm{W}$ lungs.

CONCLUSIONS: $\mathrm{W}$ improves ventilation efficiency and in vivo lung compliance in the ovine preterm lung without increasing lung inflammation or lung injury.

V ariability is an inherent property of many biological systems. Variable breathing is especially evident in newborn infants (1), particularly those born premature for whom sigh breaths with tidal volume $\left(V_{\mathrm{T}}\right)$ more than twice the average breath volume are critical to the maintenance of resting lung volume (2). Current ventilatory strategies advocated for the preterm infant focus on tightly regulating the size of each breath using volume guarantee or volume targeting of ventilator assisted/controlled breaths. An alternative approach, variable ventilation (VV), maintains a constant breath-to-breath minute volume throughout the study but distributes delivered $V_{\mathrm{T}}$ and respiratory rate (RR) such that the lung may receive $V_{\mathrm{T}}$ less than or greater than the average $V_{\mathrm{T}}$. In adult animal models, $\mathrm{VV}$ improves oxygenation and enhances gas exchange as compared with controlled conventional mechanical ventilation (CV) (3-5). Recently, we showed that $\mathrm{VV}$ enhanced both respiratory mechanics and gas exchange in preterm lambs as compared with CV that tightly regulated both breath size and rate (6), similar to findings of studies in adult animal models. However, unlike the adult animal studies, VV did not improve oxygenation in the preterm lambs, most likely due to shunting across fetal channels.

Given previous evidence that serial repeated large $V_{\mathrm{T}}$ at the initiation of ventilation in the preterm lung increases markers of inflammation and injury suggestive of volutrauma $(7,8)$, successful clinical translation of $\mathrm{VV}$ in the preterm infant requires evidence that intermittent distributed sigh breaths are not injurious to the immature lung. Although there was no evidence of increased lung inflammation or injury markers in our initial preterm lamb study (6), the experiment was designed to compare physiological outcomes for animals receiving constant and equivalent breath-to-breath minute volumes over the experimental period. The superior gas exchange efficiency of VV as compared with CV masked our ability to discriminate between the strategies with respect to lung injury due to hypoventilation in the CV group (6). In this study, we aimed to establish whether VV achieved physiological benefit without increasing evidence of ventilation-induced lung injury (VILI), using a strategy in which $V_{\mathrm{T}}$ was adjusted to target clinically accepted ranges for gas exchange. We hypothesized that in the preterm lamb, VV would achieve effective ventilation without increasing markers of lung inflammation or injury as compared with CV.

\section{RESULTS}

Baseline characteristics of gestation, birth weight, or umbilical cord blood gas variables did not differ between study groups (Table 1).

\section{Gas Exchange}

There were no differences between CV and VV groups in arterial pH $\left(P=0.772\right.$, Figure 1a) or $\mathrm{PaCO}_{2}(P=0.776$, Figure 1b) although $\mathrm{pH}$ increased in both groups over time. $\mathrm{PaCO}_{2}$ was

${ }^{1}$ Centre for Neonatal Research and Education, School of Women's and Infants' Health, University of Western Australia, Perth, Australia; ${ }^{2}$ Department of Biomedical Engineering, Boston University, Boston, Massachusetts; ${ }^{3}$ The Ritchie Centre, Monash Institute of Medical Research, Monash University, Clayton, Australia.

Correspondence: J. Jane Pillow (jane.pillow@uwa.edu.au) 
maintained in the target range after the first $40 \mathrm{~min}$ until study completion. There were no differences in oxygenation index $(\mathrm{OI})(P=0.494$, Figure 1c), or alveolar-arterial oxygen difference $\left(\mathrm{AaDO}_{2}: P=0.09\right.$, Figure $\left.1 \mathrm{~d}\right)$, between $\mathrm{CV}$ and $\mathrm{VV}$ groups, although oxygenation ( $\mathrm{OI}$ and $\mathrm{AaDO}_{2}$ ) worsened gradually over time in both groups $(P=0.002)$.

\section{Lung Function}

Permissive hypercarbia was achieved with a lower average $V_{\mathrm{T}}$ $(P=0.019$, Figure 2a), peak inspiratory pressures $(P=0.009$, Figure $2 \mathbf{b})$, and hence mean airway pressures $(P=0.009$, data

Table 1. Baseline characteristics of lambs at delivery

\begin{tabular}{|c|c|c|c|}
\hline & UVC & CV & VV \\
\hline$N$ (male) & $6(2)$ & $8(3)$ & $8(3)$ \\
\hline Gestation (d) & $128.7(0.8)$ & $128.8(0.9)$ & $129.2(0.9)$ \\
\hline Birth weight (kg) & $2.8(0.5)$ & $3.2(0.2)$ & $3.2(0.3)$ \\
\hline Cord pH & $7.2(0.1)$ & $7.1(0.1)$ & $7.1(0.1)$ \\
\hline Cord $\mathrm{PaCO}_{2}(\mathrm{~mm} \mathrm{Hg})$ & $75.7(9.0)$ & $92.6(27.3)$ & $84.9(21.6)$ \\
\hline Cord $\mathrm{PaO}_{2}(\mathrm{~mm} \mathrm{Hg})$ & $10.6(3.0)$ & $11.0(4.3)$ & $11.0(5.7)$ \\
\hline
\end{tabular}

Values displayed as mean (SD)

$\mathrm{CV}$, conventional mechanical ventilation; $\mathrm{PaCO}_{2}$, partial pressure of arterial carbon dioxide; $\mathrm{PaO}_{2^{\prime}}$, partial pressure of arterial oxygen; UVC, unventilated controls; $\mathrm{V}$, variable ventilation. not shown) in the VV group. Ventilatory efficiency index tended to be higher overall in the $\mathrm{VV}$ group $(P=0.056$, Figure $2 \mathrm{c})$, with differences evident from 120 min until study completion. There was a significant interaction between time and treatment for peak inspiratory pressure and ventilatory efficiency index $(P=0.034)$.

There was no significant change in airway resistance $(P=$ 0.236 , Figure 3a) or tissue damping $(P=0.726$, Figure $3 \mathbf{b})$ between the $\mathrm{CV}$ and VV groups at any time during the study. There was a reduction in tissue elastance (increased tissue compliance) in the VV group $(P=0.025)$, with a trend evident by as early as $20 \mathrm{~min}$ after commencing ventilation (Figure 3c).

\section{Injury Assessments}

Bronchoalveolar lavage. There was no difference in bronchoalveolar lavage (BAL) total protein concentration among controls and the CV and VV groups (Table 2). Total inflammatory cell count (monocytes and neutrophils) increased in both ventilated groups as compared with unventilated controls (Table 2) but did not differ between CV and VV $(P=0.105)$.

Lung tissue. Lung mRNA expression of connective tissue growth factor (CTGF), CYR61, early growth response protein
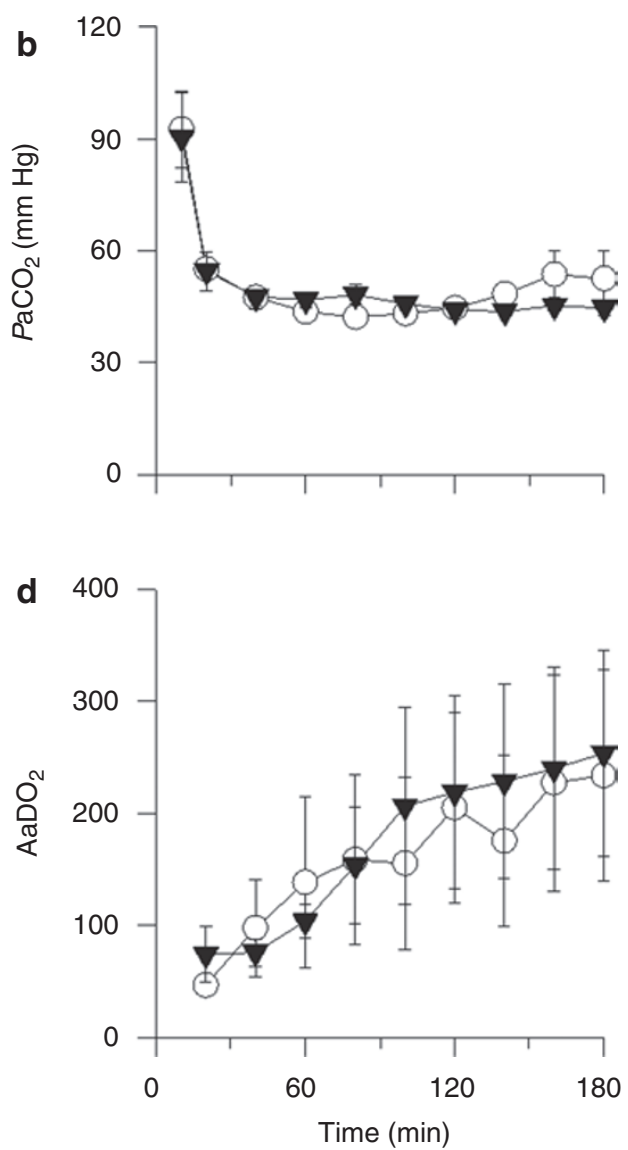

Figure 1. Blood gas outcomes over the duration of ventilation: (a) $\mathrm{pH},(\mathbf{b}) \mathrm{PaCO}_{2^{\prime}}$ (c) oxygenation index (OI), and (d) alveolar arterial oxygen tension difference $\left(\mathrm{AaDO}_{2}\right.$ ). No significant difference was evident between the two ventilation groups in gas exchange or oxygenation. $\mathrm{CV}$ : conventional ventilation (open circles); VV: variable ventilation (filled triangles). $\mathrm{PaCO}_{2^{\prime}}$ partial pressure of arterial carbon dioxide. 


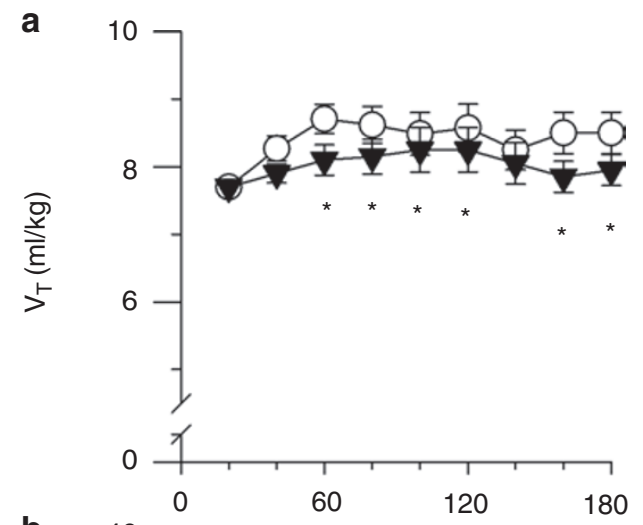

b
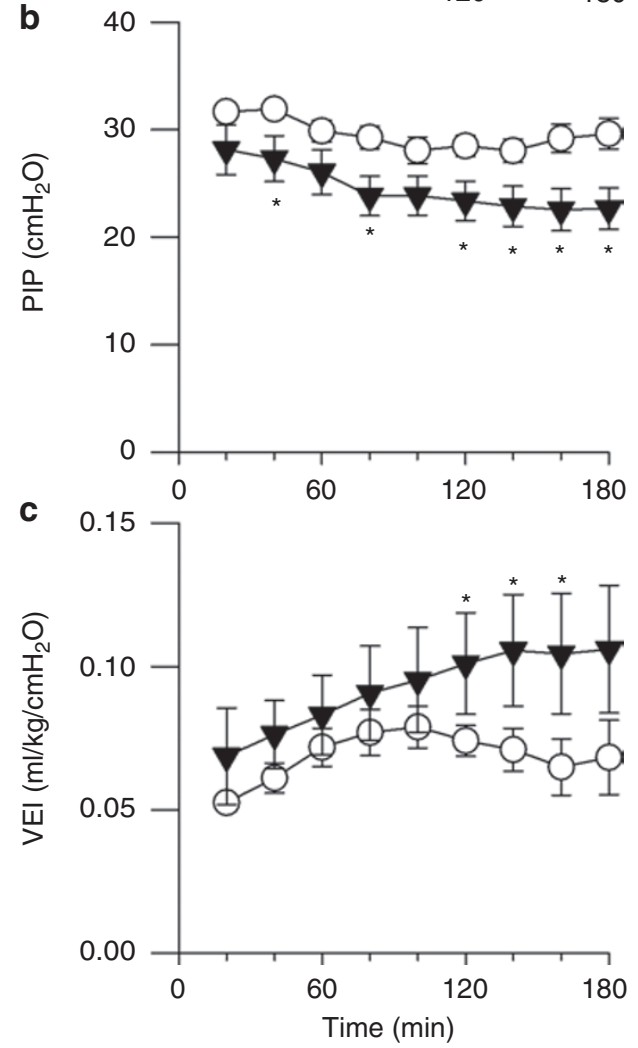

Figure 2. Ventilation efficiency outcomes: (a) $V_{\mathrm{T}} / \mathrm{kg},(P=0.023)$, (b) positive inspiratory pressure (PIP; $P=0.001)$, and (c) ventilatory efficiency index (VEl; $P=0.043)$. ${ }^{*}$ Indicates $P<0.05 \mathrm{VV}$ vs. $\mathrm{CV}$ at specific time points. Animals receiving VV had more efficient ventilation and required lower peak inspiratory pressures, despite no difference in delivered average tidal volumes. CV, conventional ventilation (open circles); $\mathrm{VV}$, variable ventilation (filled triangles). $V_{\mathrm{T}}$, tidal volume.

1 (EGR1), interleukin (IL)-1 $\beta$, and IL-6 (Figure 4) increased in all ventilation groups as compared with unventilated controls. There were no differences in mRNA expression between $\mathrm{CV}$ and VV for any mRNA marker of lung inflammation or injury.

The lungs of VV lambs had a lower wet:dry tissue ratio as compared with CV lungs $(P=0.004)$. Histological lung injury scores were not different between groups $(P=0.4$; Table 2$)$. The number of EGR1 and myeloperoxidase (MPO)-positive cells increased in lung tissue with ventilation (Figure 5) but did not differ between CV and VV groups.
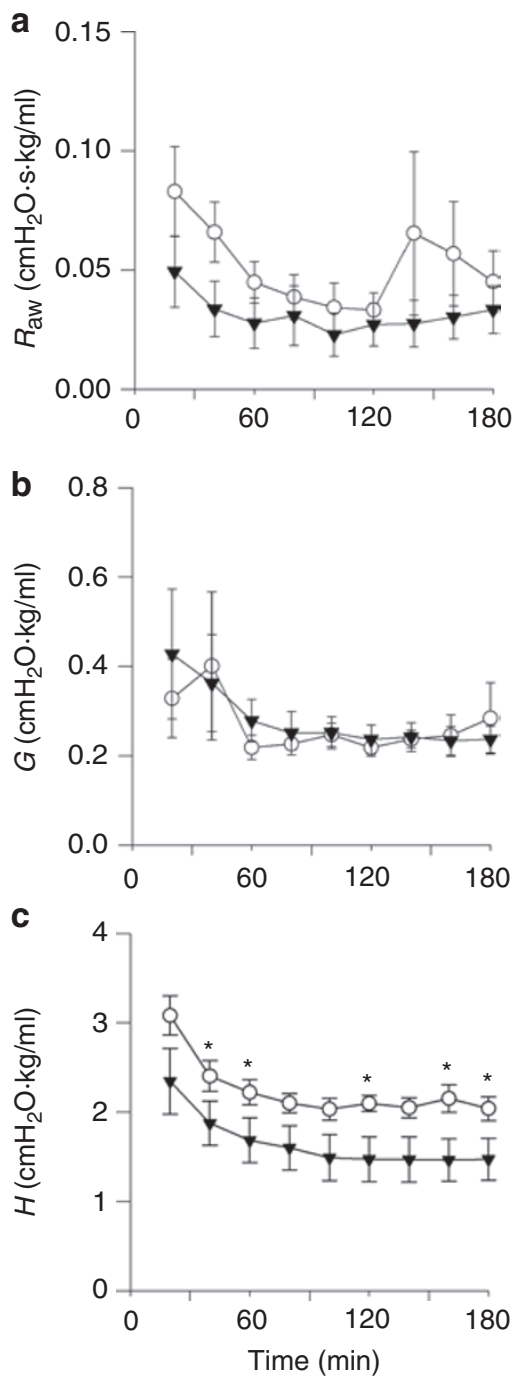

Figure 3. Low-frequency forced oscillatory mechanics: (a) airway resistance $\left(R_{\text {aw }}\right)$, (b) tissue damping $(G)$, and (c) tissue elastance $(H)$. Tissue elastance was lower (i.e., compliance was higher) in VV animals from $60 \mathrm{~min}$ until the end of the study. CV, conventional ventilation (open circles); $\mathrm{VV}$, variable ventilation (filled triangles). ${ }^{*} P<0.05 \mathrm{VV}$ vs. $\mathrm{CV}$ at specific time points.

\section{DISCUSSION}

The structurally and functionally immature preterm lung is highly vulnerable to volutrauma and subsequent development of VILI. Using a well-established preterm lamb model and a targeted hypercapnic strategy, we compared variable ventilation using a distributed pattern of $V_{\mathrm{T}}$ up to 1.5 times the average $V_{\mathrm{T}}$ and inversely variable RRs, with controlled mechanical ventilation using tightly regulated ventilatory rates and volumes. We found that despite using relatively modest intermittent increases in $V_{\mathrm{T}}, \mathrm{VV}$ provides physiological benefits (improved compliance and reduced ventilatory pressures) without increased lung inflammation or injury as compared with CV across a range of lung injury markers. These findings provide further support for incorporation of variability in breath volume and frequency as a desirable goal of neonatal conventional ventilation strategies. 
Table 2. Inflammatory markers

\begin{tabular}{lccc}
\hline & UVC & CV & VV \\
\hline $\begin{array}{l}\text { BAL protein } \\
(\mu \mathrm{g} / \mathrm{ml})\end{array}$ & $0.12(0.01,0.22)$ & $0.73(0.33,2.1)$ & $1.03(0.34,1.7)$ \\
$\begin{array}{l}\text { BAL inflammatory } \\
\text { cells }\left(10^{6} / \mathrm{kg}\right)\end{array}$ & $0.17(0,5.2)$ & $23.4(9.4,62.7)^{*}$ & $75.4(15.1,1,171)^{*}$ \\
$\quad$ & $0(0,1.5)$ & $46(8.5,82)^{*}$ & $76(46,94)^{*}$ \\
$\quad \begin{array}{l}\text { Neutrophil }(\%) \\
\quad \text { Monocyte }(\%)\end{array}$ & $0(0,2.5)$ & $8.3(1.0,13)^{*}$ & $6.8(5.0,13)^{*}$ \\
$\begin{array}{l}\text { Lung tissue injury } \\
\text { score }(/ 3)\end{array}$ & $0.6(0.3,1.2)$ & $0.7(0.3,2.0)$ & $0.7(0.6,0.9)$ \\
$\begin{array}{l}\text { Blood total WCC } \\
\left(10^{9} / \mathrm{ml}\right)\end{array}$ & $6(5,15)$ & $2.8(1.7,4)$ & $2.8(0.6,6.3)$ \\
$\quad$ & & & \\
Neutrophils $(\%)$ & $0.4(0.2)$ & $36.9(18.2)^{*}$ & $47.4(16.1)^{*}$ \\
$\quad$ Monocytes (\%) & $2.4(1.1)$ & $0.9(0.3)^{*}$ & $0.7(0.4)^{*}$ \\
\hline
\end{tabular}

Values are mean (SD) or median (range).

$\mathrm{BAL}$, bronchoalveolar lavage; CV, conventional mechanical ventilation; UVC, unventilated controls; $W$, variable ventilation; WCC, white cell count.

* $P<0.05$ vs. UVC

\section{Effect of Ventilation Pattern on Lung Function}

We investigated the physiological and injurious responses of the immature preterm lung to VV. As compared with ventilation of the preterm lung with a constant $V_{\mathrm{T}}$ and RR with $V_{\mathrm{T}}$ targeted to achieve mild permissive hypercapnea, VV enhanced ventilation efficiency and decreased in vivo lung elastance (increased lung compliance) without evidence of increased lung injury.

Studies in adult animal models over the past decade have consistently illustrated the potential benefits of variable ventilation for enhancement of ventilatory efficiency (4,9-11), increased lung compliance, (10) and improved oxygenation (12). Stochastic processes that enhance airway opening and alveolar recruitment are likely to explain the improved physiological outcomes of VV as compared with CV $(13,14)$.

We showed recently (6) that VV has similar physiological benefits when delivered to the preterm ovine lung. At equivalent breath-to-breath minute volume and average $V_{\mathrm{T}}$, $\mathrm{VV}$ enhanced $\mathrm{CO}_{2}$ clearance and increased lung volume as evidenced by increased dynamic compliance of the inflated in vivo lung but unchanged static compliance of the collapsed in situ postmortem lung. However, arterial oxygenation did not improve, most likely due to shunting across fetal vascular channels during the postnatal transition period and the lower mean airway pressures in the $\mathrm{VV}$ group resulting from the lower peak inspiratory pressures required to deliver the same $V_{\mathrm{T}}$. The initial study was designed to compare physiological outcomes for the same minute ventilation throughout the study; the resultant hypoventilation of the CV group (due to decreased ventilatory efficiency) meant we were unable to provide a clinically meaningful evaluation of the effect of $\mathrm{VV}$ on lung inflammation or injury.

Nonetheless, determination of the impact of VV onlung inflammation and injury is highly relevant for the preterm lung given its susceptibility to volutrauma and the subsequent progression to VILI. Six consecutive manual inflations of $35-40 \mathrm{ml} / \mathrm{kg}$ (approximately inspiratory capacity: 5-6 times normal breath
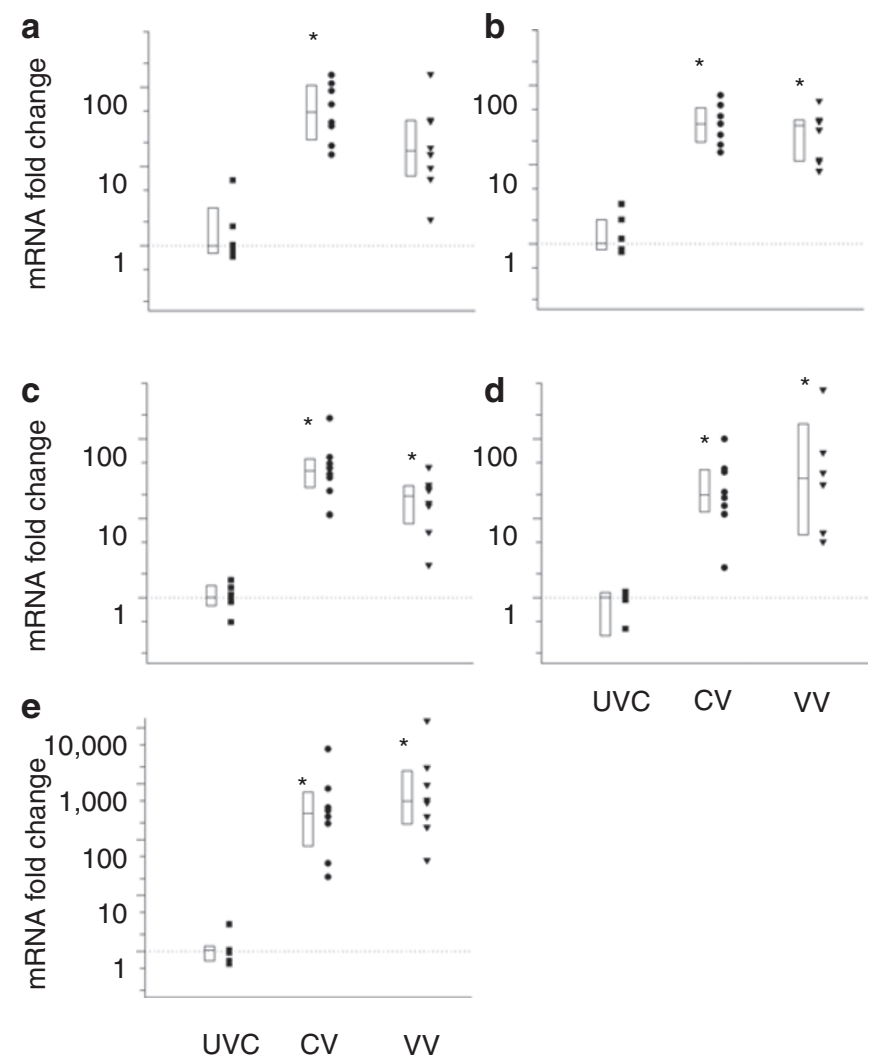

Figure 4. mRNA expression of (a) CTGF, (b) CYR61, (c) EGR1, (d) IL-1 $\beta$, and (e) IL-6. Ventilated groups had significantly higher expression of all mRNA as compared with UVC, but there was no difference between CV and VV. UVC, unventilated control (filled squares); CV, conventional ventilation (filled circles); VV, variable ventilation (filled triangles). ${ }^{*} P<0.05$ as compared with UVC. CTGF, connective tissue growth factor; CYR61, cysteine-rich 61 ; EGR1, early growth response protein 1 ; IL, interleukin.

volume) before the start of mechanical ventilation reduced subsequent lung compliance and increased histological evidence of lung injury after $4 \mathrm{~h}$ of ventilation (7). Similarly, as few as $15 \mathrm{~min}$ of a continuous breath-to-breath $V_{\mathrm{T}}$ up to twice the normal $V_{\mathrm{T}}$ of a preterm lamb initiated an injurious lung and hepatic acutephase response (8). Such observations have driven adoption of clinical strategies for preterm newborn infants that seek to avoid volutrauma arising from a large $V_{\mathrm{T}}$ by regulating the delivered $V_{\mathrm{T}}$, and in so doing, removing much of the variability inherent in normal breathing that is paramount to achieving homeokinesis. Sighs (defined as a breath with a $V_{\mathrm{T}}$ at least twice the average $V_{\mathrm{T}}$ ) are an important mechanism of regulation and maintenance of lung volume in preterm infants (2); their exclusion from ventilatory patterns may compromise respiratory function.

This study protocol differed from that used in our earlier investigation by allowing intermittent adjustment of average $V_{\mathrm{T}}$ to target mild permissive hypercarbia $\left(\mathrm{PaCO}_{2} 40-50 \mathrm{~mm}\right.$ $\mathrm{Hg}$ ) as accepted clinically for ventilation of preterm infants. The rationale for this approach was to focus on lung inflammation and injury associated with the use of VV in a preterm lung as a primary outcome measure. We achieved our target $\mathrm{PaCO}_{2}$ range within $40 \mathrm{~min}$ and this was maintained throughout the remainder of the study for both ventilation groups. 

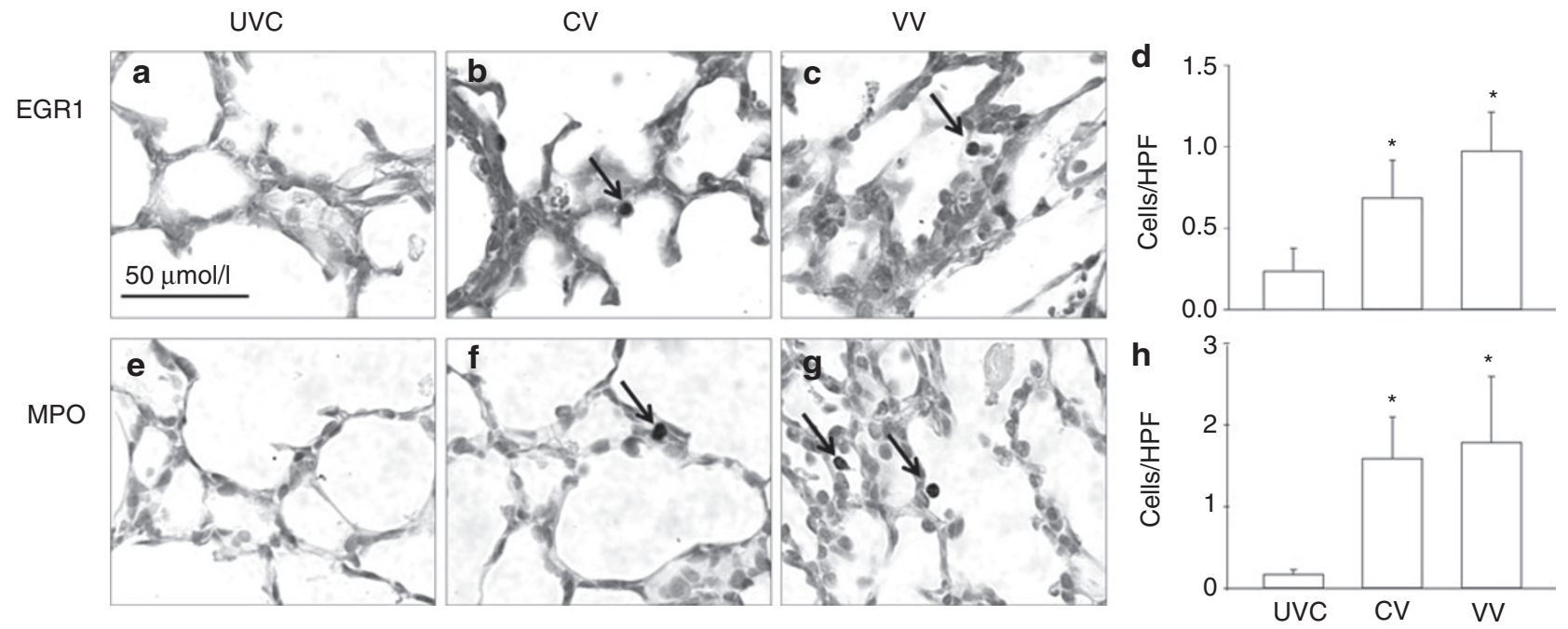

Figure 5. Immunohistochemistry analysis of (a-c) EGR1 and (e-g) MPO for unventilated controls (UVC; $\mathbf{a}$ and $\mathbf{e}$ ); conventional ventilation (CV; $\mathbf{b}$ and $\mathbf{f})$, and variable ventilation (VV; $\mathbf{c}$ and $\mathbf{g}$ ). Positive cells per high-power field (HPF) were counted in 10 random representative fields for (d) EGR1 and (h) MPO. EGR1-positive cells (b and $\mathbf{c}$, black arrows) and MPO-positive cells ( $\mathbf{f}$ and $\mathbf{g}$, black arrows) were identified in the small alveoli. Both EGR1- and MPO-positive cells increased with ventilation as compared to UVC ( $\mathbf{d}$ and $\mathbf{h}$; ${ }^{*} P<0.05$ as compared with UVC) but did not differ between CV and VV. Bar indicates $50 \mu \mathrm{mol} / \mathrm{I}$. EGR1, early growth response protein 1; MPO, myeloperoxidase.

Table 3. Tracheal tidal volume distribution at initiation of ventilation

\begin{tabular}{lcl}
\hline & $\mathrm{CV}$ & $\mathrm{VV}$ \\
\hline$V_{\mathrm{T}, \mathrm{tr}}$ mean (SD) & $7.7(0)$ & $7.7(1.5)$ \\
$V_{\mathrm{T}, \mathrm{rr}}$ median (range) & 7.7 & $7.3(5.7,12.3)$ \\
$\mathrm{RR}$ mean (SD) & $50(0)$ & $50(9)$ \\
RR median (range) & 50 & $52(31,67)$
\end{tabular}

$\mathrm{CV}$, conventional mechanical ventilation; $\mathrm{RR}$, respiratory rate (breaths $/ \mathrm{min}) ; \mathrm{V}_{\mathrm{T}, \mathrm{t}^{\prime}}$ tracheal tidal volume (ml/kg); $\mathrm{V}$, variable ventilation.

\section{Effect of Ventilation Pattern on Inflammation and Lung Injury}

Lung injury may arise from atelectatrauma (repeated inflation of collapsed alveoli), volutrauma (static or cyclic overdistension of the lung), barotrauma (injury associated with overpressurization of the lung), rheotrauma (injury associated with shear forces and high flows), and biotrauma (injury arising directly from inflammatory cells and cytokines/chemokines recruited to the lung) (15). As compared with unventilated fetal controls, the ventilated groups had increased mRNA expression of early response markers of lung injury (CTGF, CYR61, and EGR1) (16) as well as IL-1 $\beta$ and IL-6, noted previously as indicators of volutrauma in our preterm lamb model (17-19). Similarly, BAL inflammatory cells, EGR1, and MPO protein expression in the tissue were increased in $\mathrm{CV}$ and $\mathrm{VV}$ animals as compared with fetal controls, although lung tissue injury scores did not differ. These data are consistent with our earlier data showing that any mechanical ventilation of the naive preterm ovine lung results in evidence of increased inflammation and markers of lung injury (17,20-22).

However, despite using distributed $V_{\mathrm{T}}$ during $\mathrm{VV}$ that were up to 1.5 times larger than those in the CV group, there was no consistent evidence of a differential injury response between the CV and VV groups in mRNA expression of early response injury markers, BAL protein concentration, tissue injury scores, or circulating inflammatory cell counts. Of note, the VV lambs had a lower wet:dry ratio, suggesting reduced tissue fluid/edema at study completion. The lower wet:dry ratio of lung tissue may have arisen due to enhanced lung liquid clearance in association with intermittent distributed large volume, slow breaths. It is also consistent with a recent finding of enhanced clearance and/or redistribution of edema fluid following variable ventilation in pigs with oleic acid injury (23). Earlier studies of VV in adult animal models have shown decreased lung injury with VV (5,24-26), or no benefit of VV over CV $(10,27)$. No studies have shown increased lung injury with VV as compared with $\mathrm{CV}$.

Optimization of lung volume and avoidance of hypoinflation and hyperinflation is widely acknowledged as essential to avoidance of physical stress on the epithelium (28) that may be exacerbated by atelectatrauma (shear) and volutrauma (overstretch). Atelectatrauma and volutrauma are major contributors to inflammation and lung injury arising from ventilation of the surfactant-deficient, immature preterm lung that is unsupported by a highly compliant chest wall. Our measurements of lower tissue elastance in the VV group suggest that lung volume improved over time in the VV group, particularly over the first $100 \mathrm{~min}$ of the study, further supporting our earlier observations (6). Although the important role of sustained cyclic volutrauma in the initiation of lung injury is evident, our findings of no increase in injury in the VV group as compared with $\mathrm{CV}$ animals suggests that intermittent moderate increased $V_{\mathrm{T}}$ may provide physiological benefit without increasing injury.

\section{Study Limitations}

Due to resuscitation measures required at the initiation of ventilation in the preterm lamb and the need to allow fetal lung liquid to clear, our first physiological measurements 
were not scheduled until $20 \mathrm{~min}$ of age. Although lung tissue elastance decreased throughout the study in both groups of lambs, the VV group had significantly lower peak inspiratory pressures from $40 \mathrm{~min}$, and higher ventilatory efficiency index from $120 \mathrm{~min}$. Of note, the trends toward lower elastance and higher ventilatory efficiency index emerged as early as $20 \mathrm{~min}$ after the initiation of ventilation despite equivalence of cord blood gases. A similar rapid improvement in lung compliance was observed within $25 \mathrm{~min}$ of commencing VV in an earlier study in preterm lambs (6). Together, these findings suggest that retention of variability in $V_{\mathrm{T}}$ and $\mathrm{RR}$ is an important consideration during acute ventilation of the preterm lung during the immediate postnatal transition period. The early improvement in lung elastance (reflected in reduced peak inspiratory pressures and increased compliance) and lower wet:dry ratio may be important for a preterm infant with respiratory distress syndrome and requires further assessment in a longerduration study.

Similar to the findings of our earlier study (6) and despite improved lung compliance, we again did not observe a translation to improved arterial oxygenation. Oxygenation deteriorated in both ventilated groups toward the end of our study, reflecting the significant immaturity of the cardiorespiratory system. This deterioration may have resulted from a number of different factors; the relatively low positive end-expiratory pressure (PEEP) $\left(5 \mathrm{cmH}_{2} \mathrm{O}\right)$ used throughout the study in both groups may have been inadequate to maintain sufficiently high end-expiratory lung volume. Furthermore, the lower mean airway pressure in the VV group (due to lower peak inspiratory pressures associated with improved compliance) may have compromised oxygenation in that group. Our measurements of arterial oxygenation were obtained from an umbilical artery catheter, providing postductal $\mathrm{PaO}_{2}$ measurements, thus we cannot comment further on the extent to which persistence of fetal cardiac shunts influenced oxygenation.

The lack of an improvement in oxygenation in these 129-day lambs contrasts with an earlier study in slightly more mature (133-day gestation) preterm lambs exposed to maternal $\beta$ methasone a day before delivery, where we observed improved oxygenation using bubble continuous positive airway pressure (which delivers a noisy pressure signal) as compared with constant pressure continuous positive airway pressure (29). Maturation of the surfactant system and lung structure may be important factors in achieving enhanced oxygenation with the use of VV. Although an effect of VV on increased endogenous surfactant secretion is documented (24), the 128-day naive preterm lamb has almost nonexistent surfactant levels (30) as the type II epithelial cells have not fully differentiated. Therefore, we would not expect an effect of VV on alveolar surfactant levels in these lambs.

Limitation of the study duration to $3 \mathrm{~h}$ allowed examination of the early injurious response to mechanical ventilation. Although this is sufficient to establish upregulated expression of cytokine mRNA and protein expression of early markers of lung injury such as EGR1, it may not allow sufficient time for full development of either beneficial or adverse biological responses to ventilation of the preterm lung with VV; longerduration studies are therefore required to demonstrate no adverse effects of VV over a longer time-period and beyond the fetal/neonatal transition period. We also compared CV with only a single level of variability in VV. Response to VV may be enhanced by optimizing the amount of variability in the applied breathing pattern $(3,13,31)$.

The CV that was used in this study used a tightly regulated $V_{\mathrm{T}}$ and RR pattern that would only be evident in clinical practice in deeply anesthetized and/or paralyzed subjects. More typically, infants are ventilated using patient-triggered ventilatory modes that permit spontaneous breathing efforts that, provided the back-up RR is not set too high, permit inclusion of some natural variability in respiratory rhythm. Similarly, although volume-targeted or volume-guarantee ventilatory modes aim to regulate $V_{\mathrm{T}}$, recent studies by Keszler and colleagues show that the SD of $V_{\mathrm{T}}$ may be as high as $20 \%$, with $\sim 30 \%$ of measured breaths delivered outside of the target range (32). Although clinicians are often concerned with this variability in volume-targeted ventilation, our study in the preterm sheep suggests that removing such variability altogether may be physiologically detrimental, and indeed that its inclusion does not cause adverse increased inflammation. Before clinical application of VV in the human infant, consideration needs to be given to the determination of "optimal" variability of the breathing pattern for patients with different clinical conditions. Whether VV offers additional benefits over the variability already inherent in volumetargeted ventilatory modalities and in unsedated subjects requires further study.

This study was also designed to specifically examine the effect of variability on the development of inflammatory responses to mechanical ventilation. Although it is commonplace to use a PEEP of $5 \mathrm{cmH}_{2} \mathrm{O}$ during neonatal ventilation, the use of higher PEEP may promote less injurious open-lung ventilation $(33,34)$. As the beneficial effects of VV stem in part from recruitment of atelectatic lung via stochastic resonance phenomenon (13), we did not modulate PEEP to improve oxygenation in either group, as this would have masked such recruitment effects. However, as VV used a lower peak inspiratory pressure as compared with $\mathrm{CV}$, this resulted in significantly lower mean airway pressure in our VV group and may have influenced the oxygenation response. Inclusion of lung volume measurements in future comparative studies of VV with contemporary patient-triggered ventilatory modalities would guide appropriate modulation of PEEP to maintain an openlung strategy in both experimental groups.

\section{Conclusion}

In the naive, surfactant-treated preterm lamb, variable ventilation with a modest maximum $V_{\mathrm{T}}$ only 1.5 times the $V_{\mathrm{T}}$ delivered by $\mathrm{CV}$ promotes volume recruitment and increases ventilatory efficiency without increasing lung inflammation or injury. Acceptance of variability in ventilation patterns and avoidance of strategies that tightly regulate volume and frequency may be essential to optimizing physiological outcomes and reducing the 
magnitude of mechanical ventilation required for the preterm infant. Further studies need to elucidate the optimal degree of variability and to evaluate physiological and injurious responses to $\mathrm{VV}$ in the immature lung over a longer time frame and in the setting of antenatal glucocorticoid exposure.

\section{METHODS}

\section{Animal Care and Monitoring}

Animal studies were performed at Shenton Park Research Station, the University of Western Australia, and approved by the institution's animal ethics committee. At $128-130$ d gestation, Merino ewes carrying twin fetuses (term $=150 \mathrm{~d})$ were sedated $(10 \mathrm{mg} / \mathrm{kg}$ ketamine, Parnell Labs, Auckland, New Zealand; $0.02 \mathrm{mg} / \mathrm{kg}$ medetomidine, Pfizer Animal Health, NSW, Australia) before receiving a regional spinal anesthetic block ( $2 \%$ lignocaine: $3 \mathrm{ml}, 60 \mathrm{mg}$ ) and delivery by cesarean section. Ewes were euthanized $(100 \mathrm{mg} / \mathrm{kg}$ sodium pentobarbitone, Valabarb, Pitman-Moore, Australia) immediately following delivery of the second fetus by cesarean section and collection of cord blood gases. Nonventilated control lambs $(n=6)$ were euthanized at delivery (sodium pentobarbitone, $100 \mathrm{mg} / \mathrm{kg}$ ) and weighed before postmortem measurements and tissue collection.

Fetuses in ventilation groups were intubated with a cuffed $4.5 \mathrm{~mm}$ internal diameter tracheal tube after exteriorization of the head and neck. Fetal lung fluid was suctioned and intratracheal bolus surfactant (100 mg/kg poractant alpha, Chiesi Farmaceutici, Parma, Italy). was given. The fetuses were delivered, weighed, and commenced on preassigned ventilation protocols (detailed below). Propofol $(0.1 \mathrm{mg} / \mathrm{kg} /$ min, Repos, Norbrook Laboratories, Victoria, Australia) and remifentanil $(0.05 \mu \mathrm{g} / \mathrm{kg} / \mathrm{min}$, Ultiva GlaxoSmithKline, Victoria, Australia) were administered via continuous infusion through an umbilical venous catheter for anesthesia, analgesia, and suppression of spontaneous breathing. Arterial blood gas measurements were obtained at $20 \mathrm{~min}$ intervals throughout the ventilation protocol from an umbilical (postductal) arterial catheter blood sample (Rapidlab 1265, Siemens Healthcare Diagnostics, Victoria, Australia). Pulse rate and postductal oxyhemoglobin saturation $\left(\mathrm{SpO}_{2}\right)$ were monitored continuously using pulse oximetry (N-65; Covidien, Boulder, CO).

\section{Ventilation Protocol}

Initiation of Ventilation. Aeration of the lung at birth was established with a pressure-limited $\left(40 \mathrm{cmH}_{2} \mathrm{O}\right)$ sustained $(20 \mathrm{~s})$ inflation after which volume-controlled, pressure-limited $\left(40 \mathrm{cmH}_{2} \mathrm{O}\right)$ ventilation was commenced immediately without disconnection using a commercially available programmable animal ventilator (FlexiVent, Scireq, Montreal, Quebec, Canada). Regardless of group assignment, all ventilated lambs were commenced on $5 \mathrm{~cm} \mathrm{H} \mathrm{H}_{2} \mathrm{O}$ PEEP, a $1: 1.5$ inspiratory:expiratory time ratio, and an average RR of 50 breaths/ min. Initial cylinder volume $\left(V_{\text {cyl }}\right)$ was programmed to achieve an average delivered (tracheal) $V_{\mathrm{T}}$ of $7.7 \mathrm{ml} / \mathrm{kg}$ (Table 3 ).

Groups. Lambs were randomly assigned predelivery to either constant rate and constant $V_{\mathrm{T}}$ ventilation $(\mathrm{CV}, n=8)$ or to variable ventilation with a maximum $V_{\mathrm{T}}^{\mathrm{T}} 1.5$ times the average $V_{\mathrm{T}}(\mathrm{VV}, n=8)$.

Description of variable ventilation distribution. For variable ventilation, the FlexiVent was preprogrammed to deliver a range of $V_{\mathrm{T}}$. The $V_{\mathrm{T}}$ distribution used an algorithm that was developed previously to optimize alveolar recruitment in mice (26). Briefly, the distribution of $V_{\mathrm{T}}$ above the most frequently applied $V_{\mathrm{T}}$ was followed by a power law decay up to the maximum $V_{\mathrm{T}}$. Low $V_{\mathrm{T}}^{\mathrm{T}}$ values used to offset the high (recruitment) $V_{\mathrm{T}}$ were distributed uniformly below the average $V_{\mathrm{T}}$ and limited by a minimum $V_{\mathrm{T}}$ to avoid use of $V_{\mathrm{T}}$ that was insufficient to maintain ventilation (Table 3 ). $R R$ was varied inversely with $V_{\mathrm{T}}$ (average 50 breaths/min, Table 3 ).

Adjustment of ventilation and oxygenation. Delivered volume was adjusted to target a $\mathrm{PaCO}_{2}$ of $40-50 \mathrm{~mm} \mathrm{Hg}$ at intervals coincident with arterial blood gas measurements. The initial fractional inspired oxygen $\left(\mathrm{F}_{\mathrm{I}} \mathrm{O}_{2}\right)$ of 0.40 for all groups was adjusted to maintain an $\mathrm{SpO}_{2}$ of $88-95 \%$.
Physiological Outcomes and Measurements Gas exchange. OI was calculated as:

$$
\mathrm{OI}=\mathrm{P} \cdot \mathrm{F}_{\mathrm{I}} \mathrm{O}_{2} \cdot 100 / \mathrm{PaO}_{2}
$$

where $P$ is the mean pressure in the trachea and $\mathrm{PaO}_{2}$ is the partial pressure of oxygen in arterial blood.

$\mathrm{F} \mathrm{O}_{2}$ was adjusted to target a peripheral oxyhemoglobin saturation $\left(\mathrm{SpO}_{2}\right)^{2}$ of $88-95 \%$. The alveolar-arterial (aA) ratio was calculated as:

$$
\text { aA ratio }=\mathrm{PaO}_{2} /\left(713 \cdot \mathrm{F}_{\mathrm{I}} \mathrm{O}_{2}-\mathrm{PaCO}_{2}\right)
$$

where $\mathrm{PaCO}_{2}$ is the partial pressure of carbon dioxide in arterial blood and partial pressures are obtained in $\mathrm{mmHg}$.

Ventilation efficiency index (VEI) was calculated as:

$$
\mathrm{VEI}=3,800 /\left(\Delta \mathrm{P} \cdot \mathrm{RR} \cdot \mathrm{PaCO}_{2}\right)
$$

where 3,800 is a constant for production of carbon dioxide $(\mathrm{ml} \cdot \mathrm{mmHg} /$ $\mathrm{kg} \cdot \mathrm{min}), \mathrm{RR}$ is respiratory rate, and $\Delta \mathrm{P}$ is the difference between peak inspiratory pressure and PEEP.

Lung function. Cylinder displacement volume, cylinder pressure, and airway opening pressure were recorded and used to calculate tracheal $P$ and $V_{\mathrm{T}}$ after correction for the physical (impedance) properties of the circuit and tracheal tube derived from a dynamic calibration immediately before the study (35). Respiratory mechanics measured using the low-frequency oscillation technique were obtained at intervals to coincide with blood gas measurements: $P$ and volume $(V)$ measured during an optimized ventilator waveform (average $V_{\text {cyl }} 10 \mathrm{ml} / \mathrm{kg}, 0.5-13 \mathrm{~Hz}$ ) delivered by the FlexiVent were used to calculate input lung impedance. The constant-phase tissue model (36) was fitted to the impedance spectra to determine a frequency-independent airway resistance $\left(R_{\text {aw }}\right)$, and constantphase tissue damping ( $G$, similar to tissue resistance) and tissue elastance $(H)$.

Study completion/euthanasia. At $3 \mathrm{~h}$ (study completion) and after obtaining final physiological measurements, the lungs were washed in with $100 \% \mathrm{O}_{2}$ for 2 min after which the tracheal tube was clamped for $3 \mathrm{~min}$ to facilitate lung collapse by oxygen reabsorption. Lambs were euthanized with intravenous sodium pentobarbitone $(100 \mathrm{mg} / \mathrm{kg})$.

\section{Postmortem Measurements and Tissue Analysis}

Weights. The left and right lungs were weighed. Small sections of lung from the right middle lobe were weighed, dried $\left(70^{\circ} \mathrm{C}\right.$ for $\left.2 \mathrm{~d}\right)$ and reweighed to obtain wet/dry lung weights.

Bronchoalveolar lavage. The left lung was used for BAL. BAL cytospin slides were used for the blinded differential cell count of 200 cells per slide (37). BAL protein was analyzed using the Lowry method (38).

Real-time quantitative PCR ( $q R T-P C R)$. Lung pieces were cut from the right lower lobe and immediately frozen in liquid nitrogen for later qRT-PCR analysis of IL-1 $\beta$, IL-6, CTGF, Cysteine-rich 61 (CYR61), and EGR1 mRNA as described earlier (16). qRT-PCR results were analyzed using the $2^{-\Delta \Delta C T}$ method (39) where $C_{T}$ was defined as the threshold cycle number of PCRs at which amplified product was first detected, $\Delta \mathrm{C}_{\mathrm{T}}$ is the difference between the $\mathrm{C}_{\mathrm{T}}$ value of the target and housekeeping gene, and $\Delta \Delta \mathrm{C}_{\mathrm{T}}$ is the difference between the $\Delta \mathrm{C}_{\mathrm{T}}$ values for each of the two ventilatory treatment groups.

Histology and immunohistochemistry. The right upper lobe was inflation fixed with $10 \%$ formalin under a pressure of $30 \mathrm{cmH}_{2} \mathrm{O}$ for $24 \mathrm{~h}$, and randomly dissected sections were embedded in paraffin wax. Lung injury was assessed on hematoxylin and eosin stained sections using a modified acute lung injury scoring system by a blinded observer (C.A.B.); 10 high-powered fields from each animal were semiquantitatively scored $(0,1+, 2+$ and $3+)$ for infiltration of inflammatory cells in airspaces $(0=$ no infiltration, $3=$ large infiltration) $(40,41)$.

Immunohistochemical analysis was performed for MPO (Cell Marque, Rocklin, CA, no. CMC028; 1:200) and EGR1 (Santa Cruz Biotechnology, Santa Cruz, CA, no. SC-189; 1:200) (42). 


\section{Statistics}

Outcomes are expressed as mean \pm SE, unless otherwise specified. Comparisons between intervention groups used paired $t$-tests or two-way general linear model with repeated measures (parametric) or Kruskal Wallis ANOVA on ranks (nonparametric) (PASW Statistics, v18; IBM, Armonk, NY). Statistical significance was accepted at $P<0.05$.

\section{STATEMENT OF FINANCIAL SUPPORT}

This research was supported by NHMRC 458750 and the Women and Infants Research Foundation. Investigator fellowship support was provided by a Sylvia and Charles Viertel Senior Medical Research Fellowship (to J.J.P.) and a National Health and Medical Research Council and National Heart Foundation, Australia Fellowship (to G.R.P.), and National Institutes of Health grant 1R01HL098976 (to B.S.). Radiant warmer beds were provided by Fisher \& Paykel Healthcare (Auckland, New Zealand). Surfactant was donated by Chiesi Group (Parma, Italy).

\section{ACKNOWLEDGMENTS}

We express our appreciation to the members of the University of Western Australia Ovine Research Group for technical assistance and JRL Hall and Co. for provision and early antenatal care of the ewes. We also acknowledge and appreciate the technical assistance of Sven Schulzke, David Baldwin, and Roland Neumann in caring for the lambs.

\section{REFERENCES}

1. Frey U, Silverman M, Barabási AL, Suki B. Irregularities and power law distributions in the breathing pattern in preterm and term infants. J Appl Physiol 1998;85:789-97.

2. Poets CF, Rau GA, Neuber K, Gappa M, Seidenberg J. Determinants of lung volume in spontaneously breathing preterm infants. Am J Respir Crit Care Med 1997;155:649-53.

3. Arold SP, Mora R, Lutchen KR, Ingenito EP, Suki B. Variable tidal volume ventilation improves lung mechanics and gas exchange in a rodent model of acute lung injury. Am J Respir Crit Care Med 2002;165:366-71.

4. Mutch WA, Eschun GM, Kowalski SE, Graham MR, Girling LG, Lefevre GR. Biologically variable ventilation prevents deterioration of gas exchange during prolonged anaesthesia. Br J Anaesth 2000;84:197-203.

5. Spieth PM, Carvalho AR, Pelosi P, et al. Variable tidal volumes improve lung protective ventilation strategies in experimental lung injury. Am J Respir Crit Care Med 2009;179:684-93.

6. Pillow JJ, Musk GC, McLean CM, et al. Variable ventilation improves ventilation and lung compliance in preterm lambs. Intensive Care Med 2011;37:1352-9.

7. Björklund LJ, Ingimarsson J, Curstedt $\mathrm{T}$, et al. Manual ventilation with a few large breaths at birth compromises the therapeutic effect of subsequent surfactant replacement in immature lambs. Pediatr Res 1997;42:348-55.

8. Hillman NH, Moss TJ, Kallapur SG, et al. Brief, large tidal volume ventilation initiates lung injury and a systemic response in fetal sheep. Am J Respir Crit Care Med 2007;176:575-81.

9. Lefevre GR, Kowalski SE, Girling LG, Thiessen DB, Mutch WA. Improved arterial oxygenation after oleic acid lung injury in the pig using a computer-controlled mechanical ventilator. Am J Respir Crit Care Med 1996;154:1567-72.

10. Mutch WA, Buchman TG, Girling LG, Walker EK, McManus BM, Graham MR. Biologically variable ventilation improves gas exchange and respiratory mechanics in a model of severe bronchospasm. Crit Care Med 2007;35:1749-55.

11. Mutch WA, Harms S, Ruth Graham M, Kowalski SE, Girling LG, Lefevre GR. Biologically variable or naturally noisy mechanical ventilation recruits atelectatic lung. Am J Respir Crit Care Med 2000;162:319-23.

12. Mutch WA, Harms S, Lefevre GR, Graham MR, Girling LG, Kowalski SE. Biologically variable ventilation increases arterial oxygenation over that seen with positive end-expiratory pressure alone in a porcine model of acute respiratory distress syndrome. Crit Care Med 2000;28: 2457-64.

13. Suki B, Alencar AM, Sujeer MK, et al. Life-support system benefits from noise. Nature 1998;393:127-8.
14. Suki B, Barabási AL, Hantos Z, Peták F, Stanley HE. Avalanches and powerlaw behaviour in lung inflation. Nature 1994;368:615-8.

15. Jobe $\mathrm{AH}$, Ikegami M. Mechanisms initiating lung injury in the preterm. Early Hum Dev 1998;53:81-94.

16. Wallace MJ, Probyn ME, Zahra VA, et al. Early biomarkers and potential mediators of ventilation-induced lung injury in very preterm lambs. Respir Res 2009;10:19.

17. Pillow JJ, Hillman NH, Polglase GR, et al. Oxygen, temperature and humidity of inspired gases and their influences on airway and lung tissue in near-term lambs. Intensive Care Med 2009;35:2157-2163.

18. Polglase GR, Hillman NH, Ball MK, et al. Lung and systemic inflammation in preterm lambs on continuous positive airway pressure or conventional ventilation. Pediatr Res 2009;65:67-71.

19. Polglase GR, Hillman NH, Pillow JJ, et al. Positive end-expiratory pressure and tidal volume during initial ventilation of preterm lambs. Pediatr Res 2008;64:517-22.

20. Ball MK, Hillman NH, Kallapur SG, Polglase GR, Jobe AH, Pillow JJ. Body temperature effects on lung injury in ventilated preterm lambs. Resuscitation 2010;81:749-54.

21. Ball MK, Jobe AH, Polglase GR, et al. High and low body temperature during the initiation of ventilation for near-term lambs. Resuscitation 2009;80:133-7.

22. Musk GC, Polglase GR, Bunnell JB, et al. High positive end-expiratory pressure during high-frequency jet ventilation improves oxygenation and ventilation in preterm lambs. Pediatr Res 2011;69:319-24.

23. Trevisanuto D, Grazzina N, Ferrarese P, Micaglio M, Verghese C, Zanardo V. Laryngeal mask airway used as a delivery conduit for the administration of surfactant to preterm infants with respiratory distress syndrome. Biol Neonate 2005;87:217-20.

24. Arold SP, Suki B, Alencar AM, Lutchen KR, Ingenito EP. Variable ventilation induces endogenous surfactant release in normal guinea pigs. Am J Physiol Lung Cell Mol Physiol 2003;285:L370-5.

25. Boker A, Graham MR, Walley KR, et al. Improved arterial oxygenation with biologically variable or fractal ventilation using low tidal volumes in a porcine model of acute respiratory distress syndrome. Am J Respir Crit Care Med 2002;165:456-62.

26. Thammanomai A, Hueser LE, Majumdar A, Bartolák-Suki E, Suki B. Design of a new variable-ventilation method optimized for lung recruitment in mice. J Appl Physiol 2008;104:1329-40.

27. Funk DJ, Graham MR, Girling LG, et al. A comparison of biologically variable ventilation to recruitment manoeuvres in a porcine model of acute lung injury. Respir Res 2004;5:22.

28. Sandri F, Plavka R, Ancora G, et al. Prophylactic or early selective surfactant combined with nCPAP in very preterm infants. Pediatrics 2010;125:e1402-9.

29. Pillow JJ, Hillman N, Moss TJ, et al. Bubble continuous positive airway pressure enhances lung volume and gas exchange in preterm lambs. Am J Respir Crit Care Med 2007;176:63-9.

30. Pillow JJ, Jobe AH, Collins RA, et al. Variability in preterm lamb lung mechanics after intra-amniotic endotoxin is associated with changes in surfactant pool size and morphometry. Am J Physiol Lung Cell Mol Physiol 2004;287:L992-8.

31. Spieth PM, Carvalho AR, Güldner A, et al. Effects of different levels of pressure support variability in experimental lung injury. Anesthesiology 2009;110:342-50.

32. Keszler M, Nassabeh-Montazami S, Abubakar K. Evolution of tidal volume requirement during the first 3 weeks of life in infants $<800 \mathrm{~g}$ ventilated with Volume Guarantee. Arch Dis Child Fetal Neonatal Ed 2009;94:F279-82.

33. Rimensberger PC, Cox PN, Frndova H, Bryan AC. The open lung during small tidal volume ventilation: concepts of recruitment and "optimal" positive end-expiratory pressure. Crit Care Med 1999;27:1946-52.

34. Rimensberger PC, Pristine G, Mullen BM, Cox PN, Slutsky AS. Lung recruitment during small tidal volume ventilation allows minimal positive end-expiratory pressure without augmenting lung injury. Crit Care Med 1999;27:1940-5.

35. Schuessler TF, Bates JH. A computer-controlled research ventilator for small animals: design and evaluation. IEEE Trans Biomed Eng 1995;42:860-6. 


\section{Articles | Berryetal.}

36. Hantos Z, Daróczy B, Suki B, Nagy S, Fredberg JJ. Input impedance and peripheral inhomogeneity of dog lungs. J Appl Physiol 1992;72:168-78.

37. Kramer BW, Kramer S, Ikegami M, Jobe AH. Injury, inflammation, and remodeling in fetal sheep lung after intra-amniotic endotoxin. Am J Physiol Lung Cell Mol Physiol 2002;283:L452-9.

38. Lowry OH, Rosebrough NJ, Farr AL, Randall RJ. Protein measurement with the Folin phenol reagent. J Biol Chem 1951;193:265-75.

39. Andersen CC, Pillow JJ, Gill AW, et al. The cerebral critical oxygen threshold of ventilated preterm lambs and the influence of antenatal inflammation. J Appl Physiol 2011;111:775-81.
40. Jobe AH, Newnham JP, Willet KE, et al. Endotoxin-induced lung maturation in preterm lambs is not mediated by cortisol. Am J Respir Crit Care Med 2000;162:1656-61.

41. Jobe AH, Newnham JP, Willet KE, et al. Effects of antenatal endotoxin and glucocorticoids on the lungs of preterm lambs. Am J Obstet Gynecol 2000;182:401-8.

42. Dargaville PA, Aiyappan A, Cornelius A, Williams C, De Paoli AG. Preliminary evaluation of a new technique of minimally invasive surfactant therapy. Arch Dis Child Fetal Neonatal Ed 2011;96: F243-8. 